\title{
Nitrotyrosine Impairs Angiogenesis and Uncouples eNOS Activity of Pulmonary Artery Endothelial Cells Isolated From Developing Sheep Lungs
}

\author{
RU-JENG TENG, TZONG-JIN WU, C. GASTON BISIG, ANNIE EIS, KIRKWOOD A. PRITCHARD, AND GIRIJA G. KONDURI
}

Department of Pediatrics [R.-J.T., T.-J.W., A.E., G.G.K.], Cardiovascular Research Center [G.G.K.], Children Research Institute [R.-J.T., A.E., K.A.P., G.G.K.], Department of Surgery [K.A.P.], Medical College of Wisconsin, Wauwatosa, Wisconsin 53226; Departamento de

Quimica Biologica [C.G.B.], Universidad Nacional de Cordoba, Cordoba 5000, Argentina

\begin{abstract}
Infection is known to impair the growth of developing lungs. It is known that plasma free nitrotyrosine (NT) levels can reach $150 \mu \mathrm{M}$ during sepsis. Free NT incorporates into microtubules and impairs cell function. We hypothesize that free NT perturbs the angiogenic activity of pulmonary artery endothelial cells (PAEC) in developing lungs. PAEC from fetal lamb lungs were incubated with NT (1-100 $\mu \mathrm{M})$. We examined the effects of NT on tube formation, cell proliferation, apoptosis, and $\alpha$-tubulin assembly in PAEC. We assessed superoxide anion $\left(\mathrm{O}_{2}{ }^{-}\right)$and NO levels in PAEC during NT exposure. Effects of NT on endothelial NO synthase (eNOS) were examined with respect to eNOS-dimer formation and the association of eNOS chaperone, heat-shock-protein-90 (hsp90). NT decreased tube formation and increased apoptosis in PAEC. NT also decreased NO levels, increased NOS-dependent $\mathrm{O}_{2}{ }^{-}$generation, and promoted $\alpha$-tubulin depolymerization. Although NT increased eNOS homodimer formation, it decreased the hsp90 association with eNOS. Our data suggest that increased NT formation during sepsis may uncouple eNOS activity and increase oxidative stress. Because NO plays an important role in angiogenesis and vasodilation, these observations suggest a mechanism for the impaired vasodilation and angiogenesis during sepsis in the developing lung. (Pediatr Res 69: 112-117, 2011)
\end{abstract}

$\mathrm{I}^{\mathrm{n}}$ nfection is known to affect the growth of developing lungs, especially in premature infants. Premature infants are at an increased risk of bronchopulmonary dysplasia (BPD), which is characterized by impaired alveolar formation and decreased blood vessel density in the lungs (1). Previous studies have pointed out a significant association between postnatal infection and the development of BPD (2). It is known that during sepsis, increased levels of superoxide $\left(\mathrm{O}_{2}{ }^{-}\right)$and NO increase the formation of peroxynitrite (3), which nitrates tyrosine to form 3-nitrotyrosine (NT). NT can also be formed via $\mathrm{NO}_{2}$, $\mathrm{H}_{2} \mathrm{O}_{2}$ with nitrite, or myeloperoxidase-mediated processes during infection (4).

In healthy subjects, plasma concentrations of free NT are generally less than $1 \mu \mathrm{M}$ (5). During severe sepsis, free NT levels can increase to $1-150 \mu \mathrm{M}$ (6). Originally, NT was considered to be merely a footprint for increased nitrosative

Received May 17, 2010; accepted September 21, 2010.

Correspondence: Ru-Jeng Teng, M.D., Division of Neonatology, Department of Pediatrics, Medical College of Wisconsin, Suite C410, Children Corporate Center, 999N 92nd Street, Wauwatosa, WI 5322; e-mail: rteng@mcw.edu

Supported by NHLBI HL-081139-04 [K.A.P.] and a research grant from Advancing Healthier Foundation, NHLBI RO1-HL-057268 and CRI endowment fund [G.G.K.]. stress. However, emerging evidence suggests that NT is more than an innocent biomarker. Free NT impairs vascular endothelial function (7), impairs the response of systemic arteries to angiotensin II (8), and inhibits the proliferation of vascular smooth muscle cells (9). Free NT also can be incorporated into $\alpha$-tubulin, via tubulin-tyrosine ligase, to impair cytoskeleton function (10). Whether this incorporation is a reversible or irreversible process remains unclear.

The cytoskeleton plays vital roles in cell proliferation, migration/invasion, and apoptosis, all of which are involved in the process of angiogenesis. Microtubule assembly can modulate heat-shock-protein-90 (hsp90) and calmodulin, two proteins that are required for coupled endothelial NO synthase (eNOS) activity (11). Chemical reagents that alter the cytoskeleton are used to kill tumors by either inducing cell apoptosis (12) or inhibiting angiogenesis (13). NT can potentially impair the growth of developing lungs by inhibition of angiogenesis. However, the effects of NT on angiogenesis in developing lungs have not been explored previously. Here, we hypothesize that 1) free NT incorporates into microtubules of pulmonary artery endothelial cells (PAEC); 2) the incorporation of free NT impairs angiogenesis of PAEC isolated from developing lungs; and 3) free NT uncouples eNOS activity to reduce NO bioavailability. The studies were done in PAEC isolated from fetal lamb lungs delivered prematurely by cesarean section.

\section{MATERIALS AND METHODS}

The use of animals for isolation of PAEC was approved by the Medical College of Wisconsin Institutional Animal Care and Use Committee (IACUC) and conformed to the guidelines of the National Institutes of Health for the care and use of laboratory animals. PAEC were isolated from 132-d gestation fetal lambs (term $=145 \mathrm{~d}$ ) using methods we previously described (14). The pulmonary arteries were dissected up to the third generation branches in the lung, and PAEC were isolated using $0.1 \%$ collagenase type A. Cell identity was confirmed by staining for factor VIII antigen and acetylated-LDL uptake (14).

The BrdU assay kit, cell death detection kit, and in situ cell death TUNEL-POD kit were from Roche Applied Science (Indianapolis, IN). Recombinant human VEGF was obtained from NCIFCRF-Biological Resources Branch of National Cancer Institute and dihydroethidium (DHE) and

Abbreviations: DAF-FM-DA, 4-amino-5-methylamino-2', 7'-difluorofluoresceine diacetate; DHE, dihydroethidium; eNOS, endothelial NO synthase; hsp90, heat-shock-protein-90; NT, 3-nitrotyrosine; $\mathbf{O}_{2}^{-}$, superoxide anion; PAEC, pulmonary artery endothelial cell 
4-amino-5-methylamino-2', $7^{\prime}$-difluorofluoresceine diacetate (DAF-FM-DA) from Invitrogen (Carlsbad, CA). All other chemicals were obtained from Sigma Chemical Co.-Aldrich (St. Louis, MO).

Monoclonal anti- $\alpha$-tubulin antibodies (B-5-1-2 and D-M-1-A), horseradish peroxidase (HRP)-conjugated anti-rabbit IgG, Protein A-sepharose, and anti-mouse IgG were from Sigma Chemical Co.. Monoclonal antieNOS antibodies were from BIOMOL (clone H32) and Invitrogen (clone 9D10). Monoclonal anti-hsp90 antibody (clone 68) and growth-factorreduced Matrigel was from BD Biosciences (Bedford, MA). ExactaCruz E, Preclearing Matrix E, and ExactaCruz E-HRP were from Santa Cruz Biotechnology (Santa Cruz, CA). Polyclonal NT antibodies (clone 4709) and $\mathrm{Cu}, \mathrm{Zn}$-superoxide dismutase $(\mathrm{Cu}, \mathrm{Zn}-\mathrm{SOD})$ was provided by Dr. J.S. Beckman. Polyclonal anti-nitrotyrosinated- $\alpha$-tubulin antibody was from Dr. C.A. Arce. ImageJ (National Institutes of Health) software was used to analyze the band densities for Western blots.

Preparation of NT stock solution. NT from Sigma Chemical Co.-Aldrich was freshly dissolved in sterile $0.1 \mathrm{~N} \mathrm{NaOH}$ and filtered through $0.22-\mu \mathrm{m}$ filter to make $10 \mathrm{mM}$ stock solution. The $\mathrm{pH}$ of control media were adjusted with $0.1 \mathrm{~N} \mathrm{NaOH}(8.04 \pm 0.01$ versus $8.05 \pm 0.01)$. After $48 \mathrm{~h}$ in the incubator, there was no difference in $\mathrm{pH}$ between NT-containing media $(7.52 \pm 0.07)$ and $\mathrm{NaOH}$-adjusted media $(7.45 \pm 0.03)$.

Cell cultures. PAECs were cultured in DMEM with 20\% FCS in our experiments and appropriate amount of $0.1 \mathrm{~N} \mathrm{NaOH}$ was used to adjust the $\mathrm{pH}$ of the medium.

Incorporation of NT into microtubules. PAECs at $\sim 80 \%$ confluence were serum-starved $(0.5 \% \mathrm{FCS})$ for $2 \mathrm{~h}$. The medium was renewed and incubated for $48 \mathrm{~h}$ with different amounts of NT and appropriate amount of $\mathrm{NaOH}$ to adjust the $\mathrm{pH}$. One plate $(80 \mu \mathrm{M} \mathrm{NT})$ was then changed to NT-free medium for another $24 \mathrm{~h}$ for comparison. For immunoprecipitation, the cells were exposed to NT for $48 \mathrm{~h}$. PAECs were lysed in RIPA buffer and treated with Preclearing Matrix E. The supernatant was incubated with anti- $\alpha$-tubulin (B-5-1-2) antibody and ExactaCruz E. The immunoprecipitates were separated by $7.5 \%$ SDS-PAGE before transferring to nitrocellulose membranes. The membranes were blotted with polyclonal NT $(1: 5,000)$, polyclonal nitrotyrosinated- $\alpha$-tubulin (1:800), or monoclonal $\alpha$-tubulin antibody (D-M-1-A, $1: 1,000)$. Goat anti-rabbit-IgG-HRP $(1: 10,000)$ served as the secondary antibody for nitrated proteins, whereas ExactaCruz E-HRP was used for $\alpha$-tubulin. Signal was developed using enhanced chemiluminescence and autoradiography to CL-Xposure film (Pierce). Integrated optical densities (IOD) were quantified using ImageJ.

Angiogenic activities. Cell growth, apoptosis/necrosis, proliferation, and tube formation assays were performed as previously described (14).

PAECs, $1 \times 10^{5}$ per well in 12-well plate, were cultured until attached and media were renewed with/without $50 \mu \mathrm{M}$ NT. Cells were trypsinized after $48 \mathrm{~h}$ and counts (viable and nonviable) were obtained using hemocytometer after trypan-blue exclusion stain. Similar experiments were performed with 50 $\mu \mathrm{M}$ NT after adding the scavengers of reactive oxygen species, Cu,Zn-SOD $(1 \mu \mathrm{g} / \mathrm{mL})$ and/or catalase $(420 \mathrm{U} / \mathrm{mL})$, and after adding NOS antagonist, $N^{\omega}$-nitro-L-arginine methyl ester hydrochloride (L-NAME, $300 \mu \mathrm{M}$ ).

In situ TUNEL stain was used to detect apoptosis (15). PAECs $2 \times 10^{4}$ were cultured in 96-well plates, for apoptosis/necrosis and cell proliferation assays, to near confluence then serum-starved for $2 \mathrm{~h}$. The media was changed with/without $50 \mu \mathrm{M}$ NT for overnight. Anti-histone-III antibody or bromodeoxy-uridine (BrdU) was then added. Absorbance at $560 \mathrm{~nm}$ was measured after addition of the chromophore as the reflection of cell apoptosis/necrosis or proliferation, respectively (14).

Matrigel $50 \mu \mathrm{L}$ was added to each well of 96-well plate, and $2 \times 10^{4}$ of PAECs were seeded per well. Each well contained DMEM (5\% FCS) and VEGF $\left(10^{-9} \mathrm{M}\right)$ with/without NT at 1,10 , or $100 \mu \mathrm{M}$, or no VEGF/NT (controls). Tube lengths were measured for each condition.

Levels of $\mathrm{O}_{2}^{-}$and $\mathrm{NO}$ by epifluorescence. $\mathrm{NT}$ effect on $\mathrm{PAEC}_{2}{ }^{-}$levels was examined by both reduced ferricytochrome-c assay and DHE epifluorescence, whereas NO production was assessed using DAF-FM-DA epifluorescence after digitonin treatment. PAECs were incubated with NT overnight at $\sim 60 \%$ confluence. Epifluorescence expressed as integrated relative light unit (RLU) was measured by MetaVue software.

Immunofluorescent staining of microtubules. PAECs ( $~ 60 \%$ confluence) were incubated overnight with NT before fixation in cold $\left(-20^{\circ} \mathrm{C}\right)$ methanol. The slides were rehydrated (PBS with $0.1 \%$ saponin) for $1 \mathrm{~h}$, followed by blocking solution (PBS, $0.1 \%$ saponin, and $5 \%$ goat serum) for $1 \mathrm{~h}$. The slides were treated with primary antibody (B-5-1-2; 1:200) at $4^{\circ} \mathrm{C}$ overnight, washed, and incubated with FITC-conjugated anti-mouse antibody (1:320). Pictures were taken using fluorescence microscope (Ex490/Em520).

eNOS homodimer formation and hsp90 association. Homodimer formation was evaluated using low-temperature immunoblots (16). PAEC were incubated overnight in media with or without NT $(100 \mu \mathrm{M})$ at $\sim 80 \%$ confluence followed by lysis in RIPA buffer. Lysates were immunoprecipi- tated with monoclonal anti-eNOS antibody (H32). Proteins were separated by $7.5 \%$ SDS-PAGE. Monoclonal anti-eNOS antibody (9D10, 1:500) and monoclonal anti-hsp90 antibody (1:500) were used to identify the protein signals on the nitrocellulose membrane. HRP-conjugated anti-mouse IgG antibody was used $(1: 9,000)$ as the secondary antibody and exposed to CL-Xposure film after treatment with enhanced chemiluminescence. IOD of the bands were analyzed using ImageJ and IOD ratios of signals for hsp90 and corresponding eNOS were calculated for comparison.

Statistical analysis. Data were expressed as mean \pm SE. One-way ANOVA followed by Student-Newman-Keuls test was used for comparisons among more than two groups. Student $t$ test, or Mann-Whitney $U$ test, was used for comparing two groups wherever appropriate. A $p$ value $<0.05$ was considered statistically significant.

\section{RESULTS}

NT incorporates into microtubules. Immunoblots using polyclonal NT antibody showed several nitrated protein bands in cell lysates from both control and NT-treated PAEC cultures. A prominent nitrated protein band $(\sim 50 \mathrm{kD})$ was observed only in the lysates from NT-treated PAEC (Fig. 1A). This nitrated protein band corresponds to $\alpha$-tubulin and the signal increased with exposure to increasing concentrations of NT. Replacing the culture media with NT-deficient media decreased the signal of nitrated protein band (Fig. 1B), suggesting that incorporation of NT is either a reversible process or that NT is enzymatically degraded. Immunoprecipitation of $\alpha$-tubulin showed that $\alpha$-tubulin was nitrated in direct relation to NT concentrations (Fig. 1C) and the nitrotyrosinated $\alpha$-tubulin was seen only in NT-treated cells. An anti-nitrotyrosinated- $\alpha$-tubulin antibody detects NT that has been incorporated into the c-terminus of $\alpha$-tubulin (Fig. 1D) (17).

NT reduces the cell growth, decreases cell proliferation, and increases cell death. NT decreased the number of proliferating PAEC. Addition of $\mathrm{Cu}, \mathrm{Zn}$-SOD to NT-treated cultures caused further decreases in PAEC number. Catalase alone had no effect on cell counts when PAEC were incubated with NT. Addition of both catalase and $\mathrm{Cu}, \mathrm{Zn}$-SOD to NT-treated PAEC cultures increased cell counts to control levels (Fig.
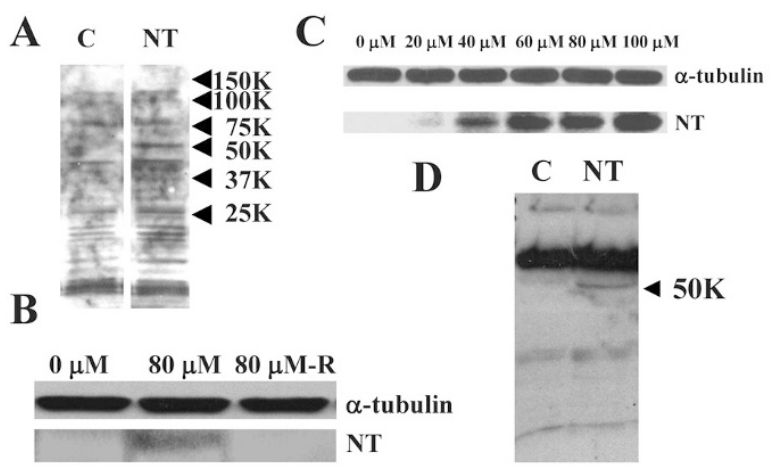

Figure 1. NT incorporates into $\alpha$-tubulin. One nitrated band $(\sim 50 \mathrm{kD})$ was seen only in NT-treated PAEC $(A)$. Immunoblot of NT-treated PAECs showed similar signals of $\alpha$-tubulin but a nitrated band with similar molecular weight as $\alpha$-tubulin that disappeared after changing back to NT-free medium for $24 \mathrm{~h}(B)$. Immunoprecipitation using anti- $\alpha$-tubulin antibody showed a dose-dependent increase in signals of nitrated $\alpha$-tubulin $(C)$. A protein band $(\sim 50 \mathrm{kD})$ was seen in NT-treated PAEC but not in control, using antinitrotyrosinated- $\alpha$-tubulin antibody, indicating that NT incorporated into the c-terminus of the $\alpha$-tubulin (D). C, control; N, NT; $80 \mu \mathrm{M}-\mathrm{R}, \mathrm{NT}$ at $80 \mu \mathrm{M}$ for $48 \mathrm{~h}$ and then recovered in NT-free media for another $24 \mathrm{~h}$. 
$2 A)$. The difference in cell counts was mainly due to difference in viable cells (Fig. $2 B$ ). These results suggest that both $\mathrm{O}_{2}{ }^{-}$ and $\mathrm{H}_{2} \mathrm{O}_{2}$ impair PAEC proliferation, whereas scavenging both radicals by the combination of $\mathrm{Cu}, \mathrm{Zn}-\mathrm{SOD}$ and catalase is protective. Addition of L-NAME to NT-treated PAEC blocked the inhibitory effects of NT on cell counts (Fig. 2C). L-NAME also tempered the $\mathrm{Cu}, \mathrm{Zn}$-SOD effect on cell counts (Fig. 2D). These data suggest that NOS-dependent $\mathrm{O}_{2}^{-}$contributes to the inhibition of PAEC proliferation by NT.

Control PAECs had low levels of apoptosis (Fig. 2E). NT increased apoptosis by nearly 2.6 -fold (Fig. $2 F$ ). Apoptosis increased to $17.4 \pm 2.4 \%, 22.4 \pm 1.9 \%$, and $28.3 \pm 1.2 \%$ as the concentration of NT increased to 1,10 , and $100 \mu \mathrm{M}$, respectively $(p<0.001$, Fig. $2 G)$. Analysis using anti-histone-
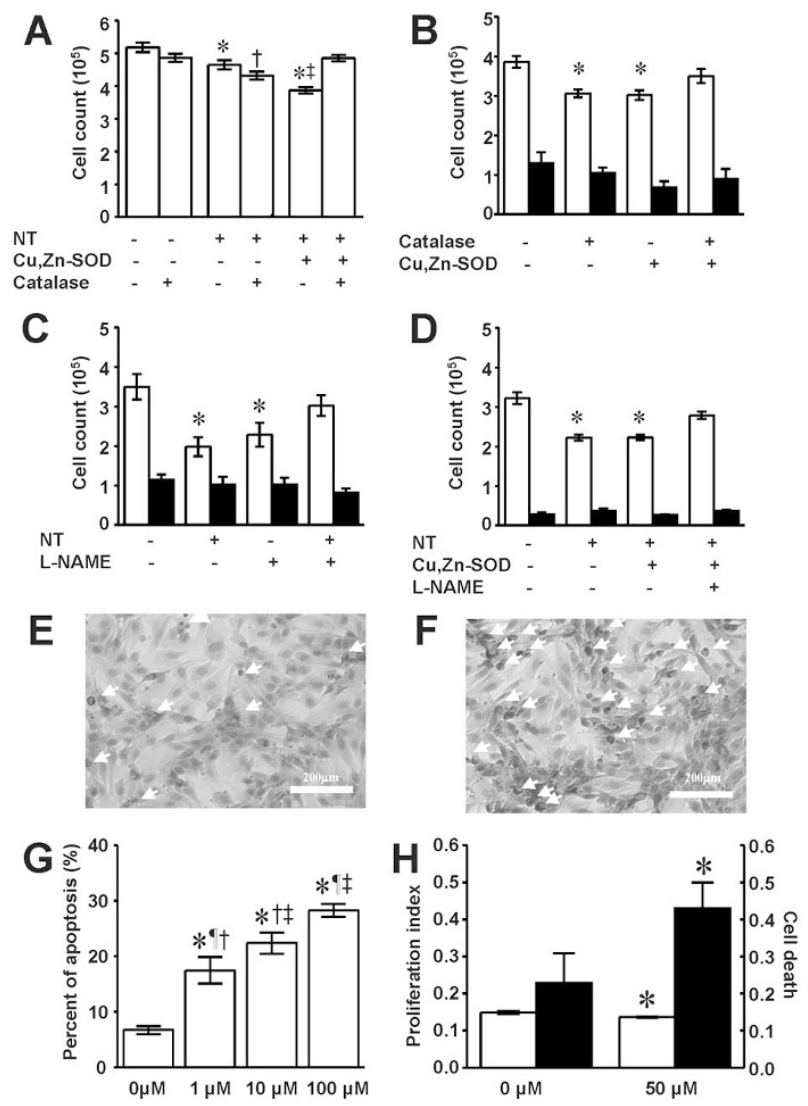

Figure 2. Cell growth, apoptosis/necrosis, and proliferation of PAEC are affected by NT. (A) The presence of SOD + CAT gave similar cell counts as controls, whereas with SOD alone, the cell counts decreased further $\left({ }^{*} p<\right.$ 0.01 vs control; ${ }^{*} p<0.01$ vs NT; ${ }^{\dagger} p<0.01$ vs both control and NT + SOD). $(B)$ In the absence of NT, both CAT alone and SOD alone decreased viable cell counts $(\square)$, whereas CAT + SOD gave similar counts as control $(* p<$ 0.05 compared with control and SOD + CAT). No difference in nonviable cell counts was seen $(\square)$; $(C)$ Both NT alone and L-NAME alone decreased viable cell counts $(\square)$, whereas NT + L-NAME gave similar counts as control $\left({ }^{*} p<0.05\right.$ compared with control and NT + L-NAME). No difference in nonviable cell counts was seen $(\square)$. (D) L-NAME ameliorates the cell count lowering effect by the combination of $\mathrm{Cu}, \mathrm{Zn}$-SOD and NT. (E) In situ TUNEL stain showed fewer apoptotic nuclei (white arrow) in controls than $(F)$ in $1 \mu \mathrm{M}$ NT. $(G)$ There was a dose-response relationship between the percentages of apoptosis and concentrations of NT $(* p<0.05$ vs control; ${ }^{\pi} p<0.05$ vs $10 \mu \mathrm{M} ;{ }^{\ddagger} p<0.05$ vs NT $1 \mu \mathrm{M} ;{ }^{\dagger} p<0.05$ vs NT $\left.100 \mu \mathrm{M}\right) .(H)$ Apoptosis/necrosis assay showed an increased index (ם), whereas the BrdU assay showed decreased proliferation with $\mathrm{NT}\left(\square,{ }^{*} p<0.05 v s\right.$ control).
III antibody showed that $50 \mu \mathrm{M}$ NT increased the index of apoptosis/necrosis from $13.9 \pm 4.0 \%$ to $26.2 \pm 4.4 \%(p=$ $0.022)$. Finally, NT $50 \mu \mathrm{M}$ decreased cell proliferation assessed by BrdU incorporation $(0.149 \pm 0.004$ versus $0.136 \pm$ 0.002 , Fig. $2 H$ ).

NT decreases tube formation. VEGF increased tube formation by control PAEC at $6 \mathrm{~h}(223.6 \pm 13.3 \%$ versus $100.0 \pm 12.4 \%, p<0.01)$ but not at $14 \mathrm{~h}(94.8 \pm 16.3 \%$ versus $127.9 \pm 7.7 \%, p=0.10$ ). NT decreased VEGF induced tube formation. At $6 \mathrm{~h}$, the total tube lengths were $77.3 \pm 8 . \%$, $68.1 \pm 3.6 \%$, and $57.0 \pm 6.9 \%$ for 1,10 , and $100 \mu \mathrm{M} \mathrm{NT}$, respectively $(p<0.001)$. These differences persisted even at $14 \mathrm{~h}(65.4 \pm 8.7 \%, 50.4 \pm 7.3 \%$, and $39.0 \pm 6.1 \%$ for 1,10 , and $100 \mu \mathrm{M}$ NT, respectively; $p<0.001$; Fig. $3 F$ ). Branching points per high-power-field were $3.2 \pm 0.6$ for unstimulated PAEC at $6 \mathrm{~h}$ and increased to $7.8 \pm 0.4$ in the presence of VEGF but no difference was seen at $14 \mathrm{~h}(2.4 \pm 0.7$ versus $2.2 \pm 0.2)$. NT decreased the branch point number to $2.2 \pm$ 0.4 and $1.2 \pm 0.4$ at $1 \mu \mathrm{M}, 1.6 \pm 0.2$ and $0.4 \pm 0.2$ at $10 \mu \mathrm{M}$, and $1.6 \pm 0.4$ and $0.6 \pm 0.2$ at $100 \mu \mathrm{M}$ for 6 and $14 \mathrm{~h}$, respectively.

NT affects polymerization of microtubules. Immunofluorescent staining for $\alpha$-tubulin showed filamentous microtubules in PAEC (Fig. 4A). The filamentous structures surrounding the perinuclear area disappeared when PAEC were incubated with $1 \mu \mathrm{M}$ NT (Fig. 4B) and $10 \mu \mathrm{M}$ NT (Fig. 4C). The more diffuse the staining, the more the microtubules are depolymerized. In the presence of $100 \mu \mathrm{M}$ NT, PAEC appeared to be smaller with a diffuse speckled pattern (Fig. $4 D$ ).
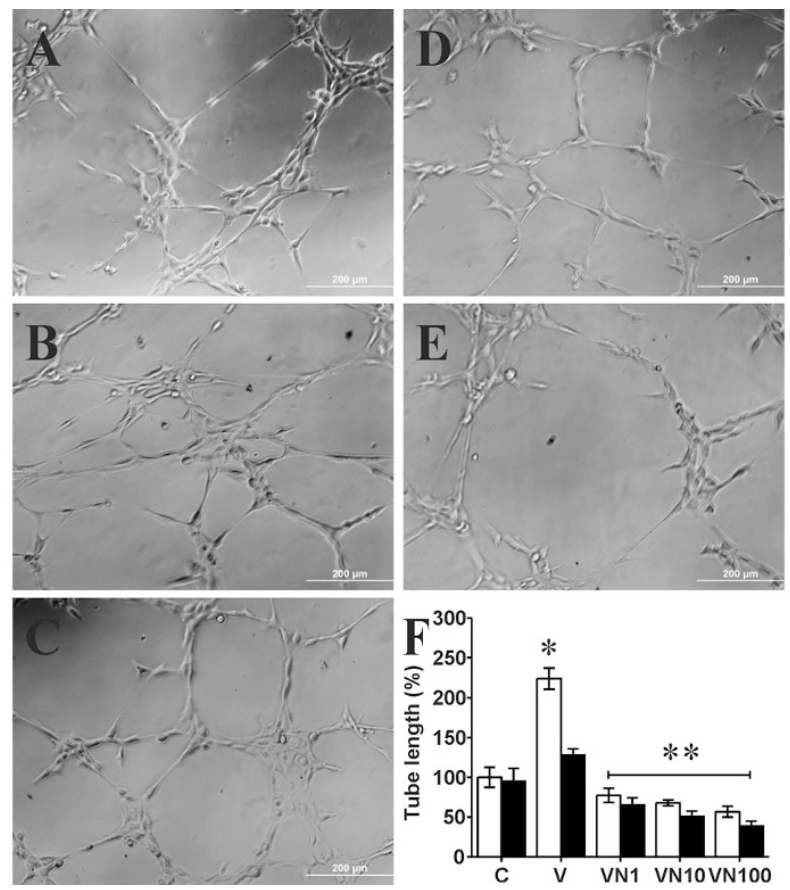

Figure 3. NT inhibits VEGF-enhanced angiogenesis in PAEC. Total tube lengths for control $(A)$ increased in the presence of VEGF $(B)$ whereas the presence of $1 \mu \mathrm{M}(C), 10 \mu \mathrm{M}(D)$, and $100 \mu \mathrm{M}(E)$ NT impaired the VEGF-enhanced tube formation. Similar findings are seen at both 6 and $14 \mathrm{~h}$ $(F, \square=6 \mathrm{~h}$ and $\boldsymbol{\square}=14 \mathrm{~h}) .{ }^{*} p<0.001$ for VEGF tube formation at $6 \mathrm{~h}$ compared with other treatments; $* * p<0.001$ for NT at both 6 and $14 \mathrm{~h}$ compared with VEGF alone. 
These images suggest that free NT increases microtubule depolymerization (18).

NT affects eNOS homodimer formation and hsp90 association. NT increased eNOS homodimer formation (Fig. $5 A)$ but decreased eNOS association with hsp90 ( 50\%) even after stimulation with eNOS agonist, ATP (Fig. 5B). As hsp90 is a required cofactor for NO synthesis, it appears that free NT uncouples eNOS by decreasing hsp 90 association rather than by increasing eNOS monomer formation.

NT affects the levels of $\mathrm{O}_{2^{-}}$and NO. NT increased both basal and ATP-stimulated DHE epifluorescence. L-NAME decreased the NT enhanced DHE epifluorescence (Fig. 6A), suggesting that NOS is the source of increased epifluorescence. Inhibition of DHE epifluorescence by SOD suggests that the increased epifluorescence with $\mathrm{NT}$ is due to $\mathrm{O}_{2}^{-}$(Fig. $6 B$ ). Similarly, using ferricytochrome-C reduction assay, PAEC cultures that were incubated with NT had increased basal $\mathrm{O}_{2}^{-}$levels (Fig. 6C).

NT decreased the DAF-FM-DA epifluorescence, both at basal level and in response to ATP stimulation (Fig. 7). L-NAME decreased DAF-FM-DA epifluorescence in the presence/absence of NT, suggesting that DAF-FM-DA fluorescence was due to NO. Taken together, these results suggest that NT uncouples eNOS activity to increases eNOS dependent $\mathrm{O}_{2}^{-}$production.
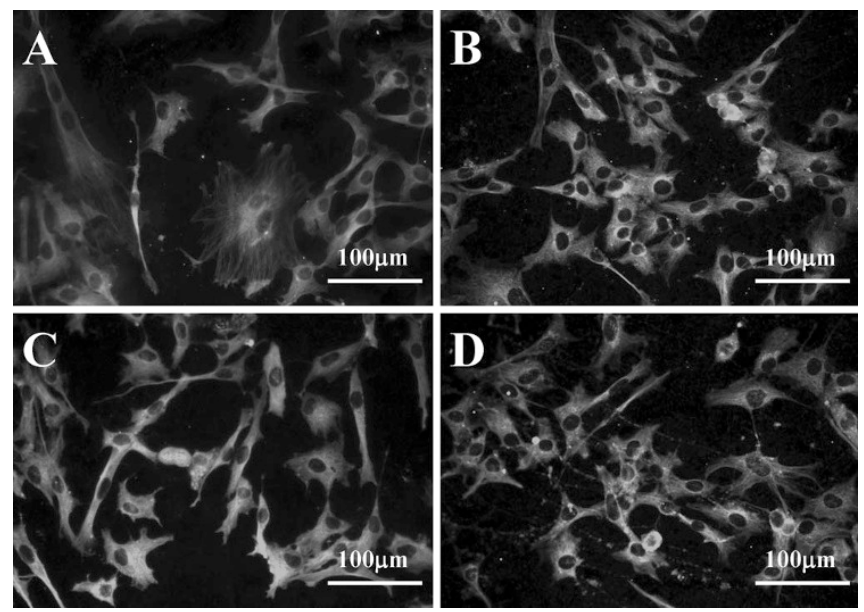

Figure 4. NT promotes depolymerization of the microtubules. Immunofluorescent staining showed well-organized microtubules in PAEC $(A)$ but the filamentous structures around the perinuclear region disappeared with $1 \mu \mathrm{M}$ $\mathrm{NT}(B)$ and became more diffuse at $10 \mu \mathrm{M}$ NT $(C)$. In the presence of $100 \mu \mathrm{M}$ NT, the cells became smaller in size and with some speckled staining for the microtubules $(D, \times 200)$.
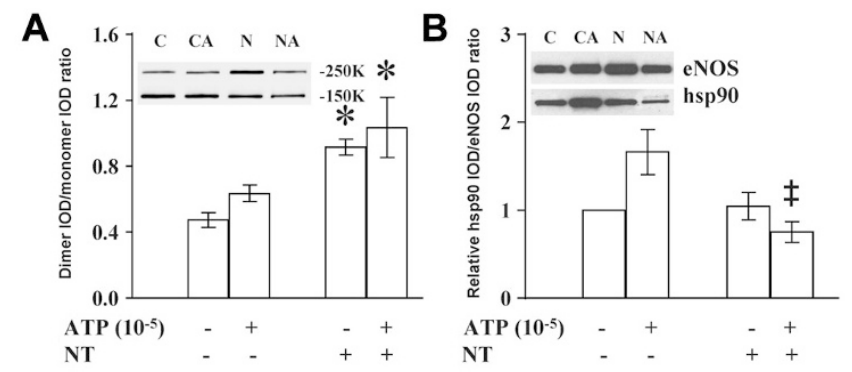

Figure 5. NT increases eNOS dimerization $(A)$ but decreases eNOS-hsp90 association $(B) .{ }^{*} p<0.05$ vs control; ${ }^{*} p<0.05$ vs control.

\section{DISCUSSION}

PAEC from prematurely delivered fetal lambs, readily incorporate free NT into $\alpha$-tubulin. This leads to microtubule depolymerization, decreased cell size, and impaired angiogenesis by PAEC. Our data also suggest that eNOS uncoupling is associated with impaired angiogenesis by NT. Using two different assays for the detection of $\mathrm{O}_{2}^{-}$, we observed that NT increases $\mathrm{O}_{2}^{-}$production in PAEC by a NOS-dependent mechanism (19). We also observed a decrease in hsp90-eNOS association after incubation with NT suggesting a mechanism for NT-induced eNOS uncoupling. These findings demonstrate that NT is more than a simple biomarker of oxidative stress and may contribute to the impaired angiogenesis observed in premature infants with infections.

The effect of NT on pulmonary vascular endothelial function, especially during the developmental stage, has not been studied before. Using PAEC from fetal lambs allows us to examine the potential effects of NT on the angiogenesis function in developing lungs. In this study, we used NT in a range of concentrations $(1-100 \mu \mathrm{M})$ that are seen during infection (6). We observed marked protein nitration in cell lysates that corresponds to $\alpha$-tubulin after NT treatment. Immunoblots using antibody that was specifically raised against nitrotyrosinated- $\alpha$-tubulin verified that NT was incorporated into $\alpha$-tubulin as previously described (17). Removal of NT from the media for $24 \mathrm{~h}$ dramatically decreases the levels of nitrated $\alpha$-tubulin in PAEC as reported earlier by Bisig et al. (17). Although the specific mechanisms for scavenging nitrated proteins in PAEC remain unknown, these data suggest that the effects of NT on PAEC function may be reversible. Because nitrotyrosinated- $\alpha$-tubulin is resistant to carboxypeptidase (10), it is possible that other enzyme systems are involved in the removal of NT or denitration of NT. We cannot rule out the possible role of normal protein turnover in the process.

Nosocomial infections develop in $20 \%$ of very LBW infants (20). Infection contributes to lung injury and increases the risk of BPD in premature infants (21). Increased formation of $\mathrm{O}_{2}^{-}$ during infection decreases $\mathrm{NO}$ availability and also generates peroxynitrite, a potent nitrating agent through the reaction between $\mathrm{NO}$ and $\mathrm{O}_{2}^{-}$. Protein nitration can affect cell function (22) and NT inhibits tumor growth (23). A potential mechanism for the alteration of cell function by NT is the posttranslational nitrotyrosination of $\alpha$-tubulin (10). Microtubules play critical roles in maintaining cell structure, intracellular transport, and mitosis. Previous studies demonstrated that a reversible, posttranslational modification of tyrosine residue occurs at the c-terminus of the $\alpha$-tubulin (24). Dynamic microtubules, characteristic of dividing cells, have tyrosine incorporated into their c-terminus (tyrosinated), whereas stable, long-lived microtubules have their tyrosine removed from the c-terminus (detyrosinated). Drugs targeting the cytoskeleton have been studied extensively as antitumor agents, and some of their effects were attributed to inhibition of angiogenesis (25). Because $\alpha$-tubulin plays a vital role in the formation of microtubules, it is possible that modification of $\alpha$-tubulin can affect cell function and differentiation $(7-9,26)$. 
A

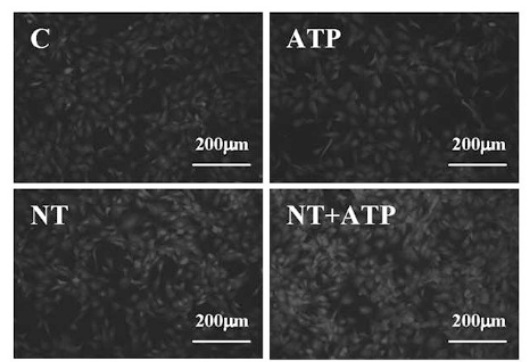

B

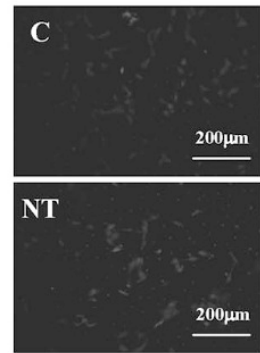

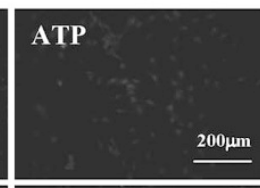

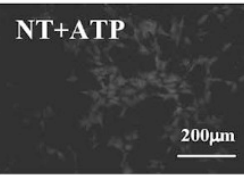

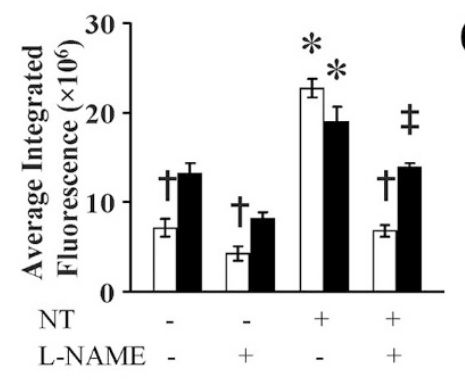

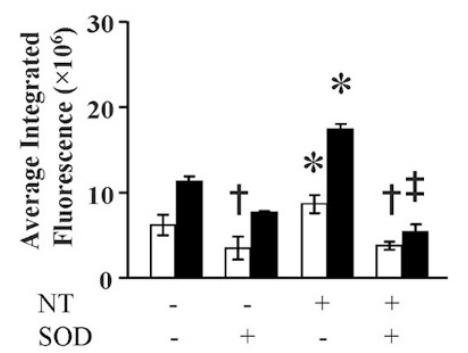

C

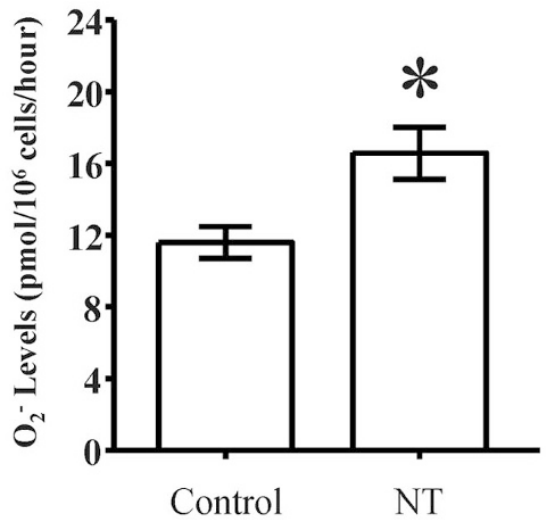

Figure 6. NT increases $\mathrm{O}_{2}^{-}$levels by PAEC. NT increased the L-NAME inhibitable $(A)$ and $\mathrm{Cu}$, Zn-SOD inhibitable $(B)$ DHE epifluorescence by PAEC both without $(\square)$ or with $(\square)$ ATP $\left(10^{-5} \mathrm{M}\right)$ stimulation. Similar results were seen also by reduced ferricytochrome-C assay $(C)$. C, control; A, ATP; N, NT; NA, NT + ATP. $* p<0.05 v s$ control; ${ }^{\dagger} p<0.05 v s$ NT without ATP stimulation; ${ }^{\ddagger} p<0.05 v s$ NT with ATP stimulation.

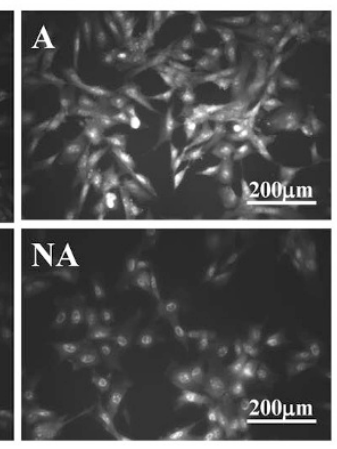

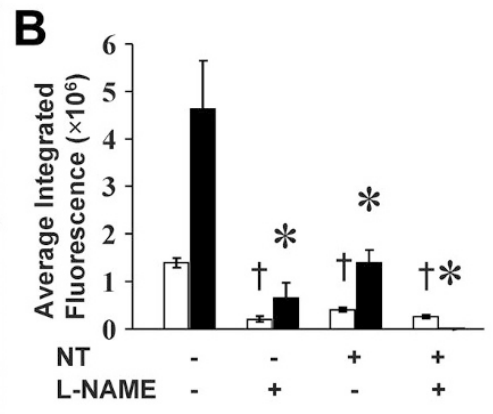

Figure 7. NT decreases NO levels by PAEC. NT treatment decreased L-NAME inhibitable DAF-FM-DA epifluorescence by $\operatorname{PAEC}(A)$. NT decreases DAF-FM-DA epifluorescence by PAEC both without and with ATP $\left(10^{-5} \mathrm{M}\right)$ stimulation $(B) . \dagger p<0.05$ compared with control without ATP stimulation $(\square) ; * p<0.05$ compared with control with ATP stimulation (ם). C, control; A, ATP; N, NT; NA, NT + ATP.
Free NT is excreted through kidneys, but impaired kidney function is commonly seen in septic premature neonates, which can lead to high plasma levels of NT. Because cell proliferation and angiogenesis are very active in the developing lungs, higher NT concentration may have a potential detrimental effect on lung development. The relationship between NT concentration in the media and signal density of nitrotyrosinated- $\alpha$-tubulin observed in our study is similar to previous reports $(9,10)$. However, unlike previous studies (10), we observed that NT incorporation into $\alpha$-tubulin is a reversible process in fetal PAECs.

Microtubule-active agents are known to modify NO production (18) and cell migration in vascular endothelial cells (27). Using nocodazole, Su et al. observed that disruption of microtubules leads to decreased NO production and hsp90-eNOS association. Our findings suggest that NT also disrupts polymerized microtubules and leads to eNOS uncoupling. We also found that NT reduces cell proliferation, as reported in other cell lines (9). Our observation that scavenging both $\mathrm{O}_{2}^{-}$and $\mathrm{H}_{2} \mathrm{O}_{2}$ improves cell counts suggests that the effect of NT is mediated by ROS. Several oxidative enzymes in PAECs can be a source of $\mathrm{O}_{2}^{-}$(28). L-NAME improved the cell counts after NT treatment, suggesting that eNOS uncoupling after NT incorporation to $\alpha$-tubulin contributes to the increased $\mathrm{O}_{2}^{-}$production.

We previously demonstrated that disrupting the interaction between hsp90 and eNOS leads to eNOS uncoupling (19). In this study, we found that NT increases eNOS homodimer formation but decreases hsp90-eNOS association. With increased $\mathrm{O}_{2}^{-}$production and decreased $\mathrm{NO}$ production, we believe that NT uncouples eNOS by blocking the interaction between hsp90 and eNOS. It is also possible that the increased $\mathrm{O}_{2}^{-}$reacted with $\mathrm{NO}$ to form peroxynitrite and nitrated the tyrosine(s) of $\alpha$-tubulin (29), which may also contribute to NT formation in our samples. It is also possible that eNOS or hsp90 is nitrated and leads to eNOS uncoupling. The later possibility deserves further investigation.

In conclusion, increased free NT, which occurs during infection, may result in altered endothelial cell biology and impaired angiogenesis. This is especially important to the developing lungs because impaired angiogenesis can affect alveolar growth and lung development (1). The limitation of our study is that we did not test our hypothesis in intact animals. Because kidneys effectively excrete free NT, it is difficult to study the in vivo effect of NT unless kidney 
function is impaired in the study animals. However, investigation of angiogenesis using cultured PAEC provides an excellent model system to obtain mechanistic information about the impaired angiogenesis. Can our findings be one of the explanations why inhalational NO therapy fails to show benefit in decreasing BPD in very premature infants remains to be determined? Future studies will address the long-term effects of NT on lung growth and differentiation in vivo.

\section{REFERENCES}

1. Abman SH 2001 Bronchopulmonary dysplasia: a vascular hypothesis. Am J Respir Crit Care Med 164:1755-1756

2. Van Marter LJ, Dammann O, Allred EN, Leviton A, Pagano M, Moore M, Martin C 2002 Chorioamnionitis, mechanical ventilation, and postnatal sepsis as modulators of chronic lung disease in preterm infants. J Pediatr 140:171-176

3. Blough NV, Zafiriou OC 1985 Reaction of superoxide with nitric oxide to form peroxonitrite in alkaline aqueous solution. Inorg Chem 24:3502-3504

4. Eiserich JP, Hristova M, Cross CE, Jones AD, Freeman BA, Halliwell B, van der Vliet A 1998 Formation of nitric oxide-derived inflammatory oxidants by myeloperoxidase in neutrophils. Nature 391:393-397

5. Frost MT, Barry Halliwell B, Moore KP 2000 Analysis of free and protein-bound nitrotyrosine in human plasma by a gas chromatography/mass spectrometry method that avoids nitration artifacts. Biochem J 345:453-458

6. Fukuyama N, Takebayashi Y, Hida M, Ischda H, Ichimori K, Nakazawa H 1997 Clinical evidence of peroxynitrite formation in chronic renal failure patients with septic shock. Free Radic Biol Med 22:771-774

7. Kooy NW, Lewis SJ 1996 Nitrotyrosine attenuates the hemodynamic effects of adrenoceptor agonists in vivo: relevance to the pathophysiology of peroxynitrite. Eur J Pharmacol 310:155-161

8. Mihm MJ, Jing L, Bauer JA 2000 Nitrotyrosine causes selective vascular endothelial dysfunction and DNA damage. J Cardiovasc Pharmacol 36:182-187

9. Phung AD, Soucek K, Kubala L, Harper RW, Bulinski JC, Eiserich JP 2006 Posttranslational nitrotyrosination of alpha-tubulin induces cell cycle arrest and inhibits proliferation of vascular smooth muscle cells. Eur J Cell Biol 85:1241-1252

10. Eiserich JP, Estevez AG, Bamberg TV, Ye YZ, Chumley PH, Beckman JS, Freeman BA 1999 Microtubule dysfunction by posttranslational nitrotyrosination of alphatubulin: a nitric oxide-dependent mechanism of cellular injury. Proc Natl Acad Sci USA 96:6365-6370

11. Czar MJ, Welsh MJ, Pratt WB 1996 Immunofluorescence localization of the 90-kDa heat-shock protein to cytoskeleton. Eur J Cell Biol 70:322-330

12. Wang LG, Liu XM, Kreis W, Budman DR 1999 The effect of antimicrotubule agents on signal transduction pathways of apoptosis: a review. Cancer Chemother Pharmacol 44:355-361

13. Hotchkiss KA, Ashton AW, Mahmood R, Russell RG, Sparano JA, Schwartz EL 2002 Inhibition of endothelial cell function in vitro and angiogenesis in vivo by
Docetaxel (Taxotere): association with impaired repositioning of the microtubule organizing center. Mol Cancer Ther 1:1191-1200

14. Teng RJ, Eis A, Bakhutashvili I, Arul N, Konduri GG 2009 Increased superoxide production contributes to the impaired angiogenesis of fetal pulmonary arteries with in utero pulmonary hypertension. Am J Physiol Lung Cell Mol Physiol 297:L184-L195

15. Sgonc R, Boeck G, Dietrich H, Gruber J, Recheis H, Wick G 1994 Simultaneous determination of cell surface antigens and apoptosis. Trends Genet 10:41-42

16. Klatt P, Schmidt K, Lehner D, Glatter O, Bächinger HB, Mayer B 1995 Structural analysis of porcine brain nitric oxide synthase reveals a role for tetrahydrobiopterin and L-arginine in the formation of an SDS-resistant dimer. EMBO J 14:3687-3695 HB

17. Bisig CG, Purro SA, Contin MA, Barra HS, Arce CA 2002 Incorporation of 3-nitrotyrosine into the $\mathrm{C}$-terminus of $\alpha$-tubulin is reversible and not detrimental to dividing cells. Eur J Biochem 269:5037-5045

18. Su Y, Zharikov SI, Block ER 2002 Microtubule-active agents modify nitric oxide production in pulmonary artery endothelial cells. Am J Physiol Lung Cell Mol Physiol 282:L1183-L1189

19. Konduri GG, Bakhutashvili I, Eis A, Pritchard K Jr 2007 Oxidant stress from uncoupled nitric oxide synthase impairs vasodilation in fetal lambs with persistent pulmonary hypertension. Am J Physiol Heart Circ Physiol 292:H1812-H1820

20. Stoll BJ, Gordon T, Korones SB, Shankaran S, Tyson JE, Bauer CR, Fanaroff AA, Lemons JA, Donovon EF, Oh W, Stevenson DK, Ehrenkranz RA, Papile L-A, Verter J, Wright LL 1996 Late-onset sepsis in very low birth weight neonates: a report from the National Institute of Child Health and Human Development Neonatal Research Network. J Pediatr 129:63-71

21. Kallapur SG, Jobe AH 2006 Contribution of inflammation to lung injury and development. Arch Dis Child Fetal Neonatal Ed 91:F132-F135

22. Peluffo G, Radi R 2007 Biochemistry of protein tyrosine nitration in cardiovascular pathology. Cardiovasc Res 75:291-302

23. MacLean SJ, Huber RE 1971 The effects of DL-p-fluorophenylalanine and L-3 nitrotyrosine on the growth and biochemistry of the Taper liver tumor. Cancer Res 31:1669-1672

24. Barra HS, Arce CA, Argaraña CE 1988 Post-translational tyrosination/ detyrosination of tubulin. Mol Neurobiol 2:133-153

25. Hinnen P, Eskens FA 2007 Vascular disrupting agents in clinical development. Br J Cancer 96:1159-1165

26. Chang W, Webster DR, Salam AA, Gruber D, Prasad A, Eiserich JP, Bulinski JC 2002 Alteration of the c-terminal amino acid of tubulin specifically inhibits myogenic differentiation. J Biol Chem 277:30690-30698

27. Lu H, Murtagh J, Schwartz EL 2006 The microtubule binding drug Laulimalide inhibits vascular endothelial growth factor-induced human endothelial cell migration and is synergistic when combined with Docetaxel (Taxotere). Mol Pharmacol 69:1207-1215

28. Li PF, Dietz R, von Harsdorf R 1997 Differential effect of hydrogen peroxide and superoxide anion on apoptosis and proliferation of vascular smooth muscle cells Circulation 96:3602-3609

29. Tedeschi G, Cappelletti G, Negri A, Pagliato L, Maggioni MG, Maci R, Ronchi S 2005 Characterization of nitroproteome in neuron-like PC12 cells differentiated with nerve growth factor: Identification of two nitration sites in $\alpha$-tubulin. Proteomics $5: 2422-2432$ 